\title{
Isotope ratio mass spectrometry application for environmental investigations
}

\author{
Galina Simonova ${ }^{1}$, and Daria Kalashnikova ${ }^{1, *}$ \\ ${ }^{1}$ Institute of Monitoring of Climatic and Ecological Systems of Siberian Branch of the Russian \\ Academy of Sciences (SB RAS), 634055, 10/3, Academichesky Ave., Tomsk, Russia
}

\begin{abstract}
Stable isotope ratio mass spectrometry (IRMS) is a useful technique with a broad range of applications. Stable isotopes are important indicators of environmental changes (including climate), and can be used to explain the functioning of biogeochemical cycles. Examples of IRMS aplications in the fields of environmental science, paleoecology/climatology, and analysis of atmospheric pollution are presented in this paper. These studies were carried out using an isotope mass spectrometry complex (Tomsk Regional Core Facilities of Tomsk Scientific Center of Siberian Branch of the Russian Academy of Sciences (SB RAS)) at the Institute of Monitoring of Climatic and Ecological Systems of SB RAS.
\end{abstract}

\section{Introduction}

Light elements $(\mathrm{C}, \mathrm{H}, \mathrm{O}, \mathrm{N})$ are important components of many compounds in the Earth's ecosystems. IRMS is one of various methods for determination of the concentration of these light elements, and their isotope composition in natural objects [1,2].

Isotopes are two or more forms of an element with the same number of protons but differing numbers of neutrons. These isotopes differ in mass. Isotopes can exist in both stable and unstable (radioactive) forms. The stable isotopes of the light elements are of biological interest. For example, carbon has two stable isotopes ${ }^{12} \mathrm{C}$ and ${ }^{13} \mathrm{C}$, the terrestrial abundance of which is $98.89 \%$ and $1.11 \%$, respectively. The stable isotope ratios are not the same for each element in various natural objects. Therefore, one of the main IRMS applications is the determination of the objects (substance) origin. Changes in isotope composition are caused by isotope fractionation within natural, chemical, climatic and anthropogenic processes [3].

Stable isotope composition can be measured commonly by elemental analyzer coupled to isotope ratio mass spectrometer. Isotope composition is defined as

$$
\delta^{n} X=\left[\frac{R_{\text {sample }}-R_{\text {standard }}}{R_{\text {standard }}}\right] \times 1000, \quad(\% 0)
$$

\footnotetext{
*Corresponding author: terrezaprk@mail.ru
} 
where ${ }^{n} X-{ }^{2} \mathrm{H},{ }^{13} \mathrm{C},{ }^{15} \mathrm{~N},{ }^{18} \mathrm{O}, R_{\text {sample }}$ and $R_{\text {standard }}$ are the ratio of heavy isotope to light isotope in the sample and in the standard, respectively, and determined as

$$
R=\frac{\text { abundance of the heavy isotope }}{\text { abundance of the light isotope }} \text {. }
$$

The result is related to appropriate internationally certified reference material.

\section{IRMS for paleoecology}

\subsection{Carbon isotope composition as a paleoclimate proxy in peat}

Stable carbon isotopes are considered a very effective tool for studying the physical and biological aspects of the global ecosystem functions. Results of the analysis of the carbon isotope composition $\left(\delta^{13} \mathrm{C}\right)$ for cellulose and humic acids in the Bakcharskoye oligotrophic bog peat (Tomsk region) are presented in this paper. Thickness of the peat deposit is 230 $\mathrm{cm}$. The beginning of peat accumulation dates from $2480 \pm 80$ BP (radiocarbon years) according to Golovatskaya [4].

Radiocarbon age was determined by a liquid scintillation method using a 1220 Quantulus spectrometer-radiometer, and the stable carbon isotope ratio analysis was carried out by the isotope mass spectrometric complex (Tomsk Regional Core Facilities of Tomsk Scientific Center SB RAS). The $\delta^{13} \mathrm{C}$ was analyzed by a Flash 2000 Elemental Analyzer coupled to a DELTA V Advantage isotope ratio mass spectrometer. The isotope composition was measured relative to the reference gas which was calibrated relative to cellulose reference material (IAEA-CH-3). The measurement error did not exceed $\pm 0.1 \%$. Figure 1 shows the variation of the $\delta^{13} \mathrm{C}$ for peat and temperature values in central Greenland. Variations of temperature in Greenland [5] were selected for the model of temperature variation in the Northern Hemisphere because reconstructed temperature data was not found for a territory close to the Tomsk region.

a)
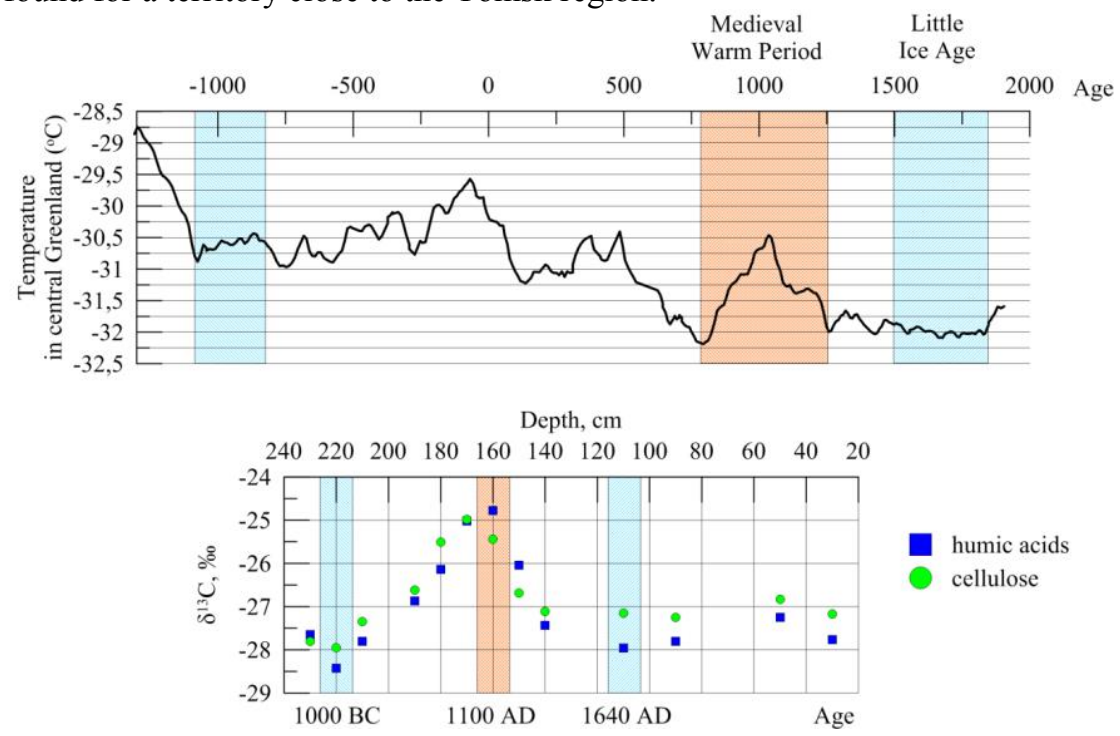

Fig.1. Comparison of the Northern Hemisphere temperature over the past 3500 years of Holocene and the $\delta^{13} \mathrm{C}$ of peat: a) temperature in central Greenland (temperature is reconstructed by the isotope composition of ice core); b) cellulose and humic acids $\delta^{13} \mathrm{C}$ of the Bakcharskoye oligotrophic bog peat. 
Enrichment of ${ }^{13} \mathrm{C}$ can be caused by an ambient temperature increase which stimulates metabolic processes in plants, and hence more heavy isotopes $\left({ }^{13} \mathrm{C}\right)$ are absorbed by plants during photosynthesis. Increase in the ${ }^{13} \mathrm{C}$ content (i.e. higher $\delta^{13} \mathrm{C}$ values) in peat cellulose samples taken from $150-160 \mathrm{~cm}$ is observed in the obtained data. The results of radiocarbon dating showed the peat samples from 150 and $160 \mathrm{~cm}$ have calendar ages 1040-1220 AD and 890-1160 AD correspondingly (Figure 1b). In accordance with the temperature data [5] during this time in the Northern Hemisphere, a warm climate (Medieval Warm Period) was observed and confirmed by the measured $\delta^{13} \mathrm{C}$ values. Depletion of the isotope composition by ${ }^{13} \mathrm{C}$ is found at a depth of 110 and $220 \mathrm{~cm}$. These depths correspond to the radiocarbon age of $262 \pm 82 \mathrm{BP}$ (or $1633 \mathrm{AD}$ - median probability cal. year) and $2854 \pm 102 \mathrm{BP}$ (or $1047 \mathrm{BC}$ - median probability cal. year). These time intervals correspond to cooling periods (Figure 1a).

\subsection{Carbon isotope composition as an anthropogenic proxy in tree rings}

Palaeoclimatic reconstructions are typically based on functions describing the empirical relationship between isotopic and climatic parameters. These empirical relationships may change depending on a variety of external factors (the site conditions, species and time frame studied, and anthropogenic impact).

Over the last two centuries, human activity has led to significant environmental changes. An exponential increase in the concentration of carbon dioxide in the atmosphere caused mainly by the burning of fossil fuels is among these changes. Burning of fossil fuel dilutes the proportion of ${ }^{14} \mathrm{C}$ and ${ }^{13} \mathrm{C}$ isotopes relatively to ${ }^{12} \mathrm{C}$ in atmospheric $\mathrm{CO}_{2}$ by adding carbon, which is partially depleted in ${ }^{13} \mathrm{C}$ and entirely depleted in ${ }^{14} \mathrm{C}$. This process is referred to as the Suess effect. The values of $\delta^{13} \mathrm{C}$ of atmospheric $\mathrm{CO}_{2}$ show a globally decreasing tendency in the period of $1850-2008$ : from $-6.45 \%$ to $-8.08 \%$ [ [6].

Annual rings of trees are interesting subjects for studying natural-climatic and anthropogenic processes. Changes in $\delta^{13} \mathrm{C}$ cellulose of annual tree rings are determined by the features of fractionation of carbon isotopes during the formation of each ring. We have considered the possibility of using $\delta^{13} \mathrm{C}$ tree-ring chronologies to identify and recognize changes in forest ecosystems located far from the industrial zones of Tomsk city in the south of the West Siberian Plain. The average age of the trees in the studied area was 75 years. The age of the analyzed Larix sibirica was 205 years. The obtained $\delta^{13} \mathrm{C}$-tree ring record for cellulose was covering a range of 1912-2010 years (Figure 2).

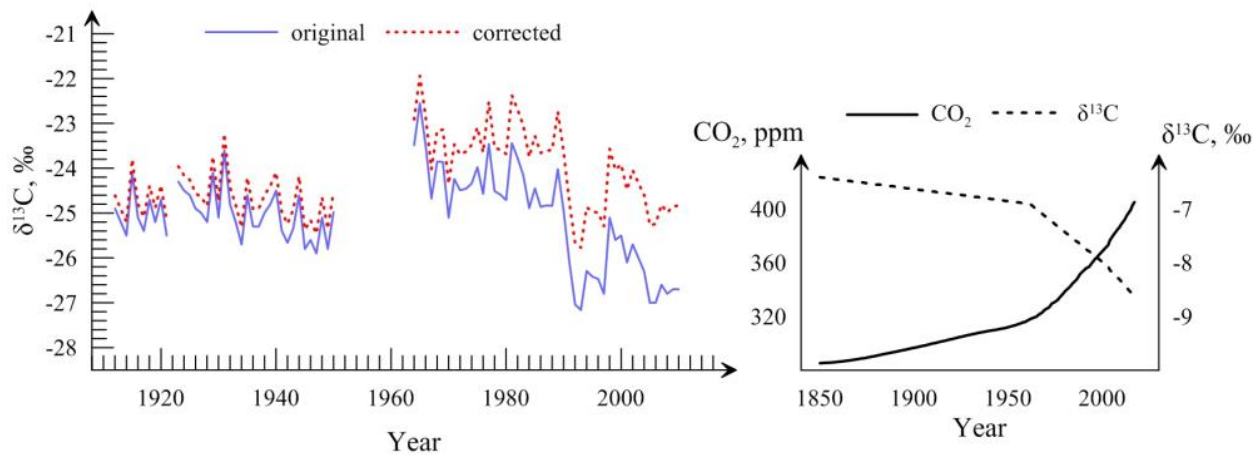

Fig. 2. $\delta^{13} \mathrm{C}$-tree rings record of Larix sibirica (left figure) and the concentration and $\delta^{13} \mathrm{C}$ of atmospheric $\mathrm{CO}_{2}$ in the industrial period (after $1850 \mathrm{AD}$ ) (right figure).

Unfortunately, data for several years was missing in our study due to insufficient amounts of wood that were required for IRMS analysis. The data was corrected by 
considering the changes in $\delta^{13} \mathrm{C}$ values of atmospheric $\mathrm{CO}_{2}$ caused by the Suess effect (Figure 2) [7]. The graph shows the contribution to the carbon isotope composition of cellulose brought by anthropogenic emissions from burned fuel.

We did not detect statistically significant relationships of $\delta^{13} \mathrm{C}$-tree rings record with climatic parameters. However, the graph clearly shows changes of values of $\delta^{13} \mathrm{C}_{\text {corr }}$-tree rings. The development history of the forest stand was restored using the data of annual ring width of Pinus sylvestris trees growing next to Larix sibirica tree selected. According to the forest stand history, three fellings were made in the studied area over the periods of 1912-2010: 1936-1937, 1955-1956, and 1985-1986.

The values of $\delta^{13} \mathrm{C}_{\text {corr }}$ wood components most often have a positive correlation with air temperature fluctuations, and a negative correlation with changes in the relative humidity and the amount of atmospheric precipitation [7]. This is confirmed by the correlation analysis of the $\delta^{13} \mathrm{C}_{\text {corr-tree }}$ rings record and the time series of meteorological parameters performed separately for three periods: 1912-1950, 1964-1990 and 1991-2010. The abrupt changes of the $\delta^{13} \mathrm{C}_{\text {corr }}$-tree rings record after the second and third felling were apparently caused by a decrease in the competition between trees for soil moisture after selective felling. Thus, the $\delta^{13} \mathrm{C}$-tree rings record contains a climatic signal and information on disturbances in forest ecosystems that can be detected by isotope analysis despite the optimal tree growth conditions.

\section{IRMS analysis of atmospheric pollution}

IRMS allows us to trace the belonging of atmospheric pollutants to its origin source at an atomic level. Stable isotope ratios of organic substance light elements forming biofuels or objects of living nature differ from each other. This phenomena is used as an isotope marker for determining an origin source of atmospheric pollution. Figure 3 shows variations in the isotope composition of nitrogen $\left(\delta^{15} \mathrm{~N}\right)$ in environmental objects.

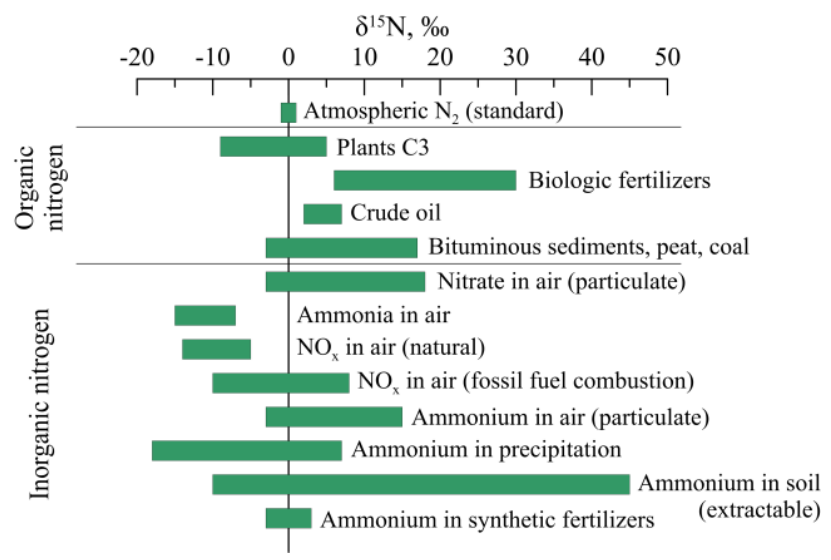

Fig. 3. Variations of $\delta^{15} \mathrm{~N}$ in natural objects.

$\delta^{15} \mathrm{~N}$ of plants reflects pollution of the environment to a greater degree, and is one of the main markers of anthropogenic pollution. According to both foreign and Russian researchers, epiphytic mosses and lichens are more preferable for monitoring the condition of air than other vascular plants because of their higher ability to accumulate pollutants.

The content of nitrogen in mosses and lichens is proportional to its concentration in the atmosphere. $\delta^{15} \mathrm{~N}$ can be used to study the arrival and migration of nitrogen-containing contaminants. Mosses (Leskea polycarpa) and lichens (Hypogymnia physodes, Flavoparmelia caperata) growing in Tomsk, Prokopyevsk, and Khanty-Mansiysk were 
chosen for this study. Tomsk is the administrative center of the Tomsk region with developed industry. Prokopyevsk is one of the major coal-mining cities of the Kemerovo region. Khanty-Mansiysk is an ecologically clean city, in which there are no large industrial enterprises.

The isotope composition of mosses is heavier than the isotope composition of lichens, due to the difference in their biochemistry and physiology. The average values of $\delta^{15} \mathrm{~N}$ in lichens for Khanty-Mansiysk, Prokopyevsk, and Tomsk are $-7.3 \pm 1.3 \%$ o, $-4.9 \pm 1.4 \%$, and $1.3 \pm 1.5 \%$, correspondingly. The average value of $\delta^{15} \mathrm{~N}$ in mosses for Tomsk is $+2.1 \pm 1.5 \%$, which is heavier than the average for Prokopyevsk $(-1.0 \pm 1.4 \%$ ) and Khanty-Mansiysk ($0.1 \pm 1.7 \%$ ). The enriched in ${ }^{15} \mathrm{~N}$ isotope compositions of nitrogen of mosses and lichens indicate a greater contribution of sources emitting oxidized forms of $\mathrm{N}$ (transport, industrial facilities, power plants and individual heating systems). Negative values of $\delta^{15} \mathrm{~N}$ in plants indicate the predominance of ammonia forms of emissions (according to Figure 3 ). The comparison of the average values of $\delta^{15} \mathrm{~N}$ between cities allows us to postulate that Tomsk has a larger anthropogenic load in terms of emissions of nitrogen-containing compounds.

The studies of isotope composition of atmospheric aerosols deposited on the snow cover in Tomsk also showed a heavy $\delta^{15} \mathrm{~N}$ in the Tomsk city center [8]. The values of $\delta^{15} \mathrm{~N}$ of water-insoluble fractions of aerosol particles were $+6.3 \%$ in the downtown and $+3.8 \%$ for Tomsk vicinities. This value is comparable with the values of isotope composition of insoluble nitrogen-containing aerosol particles released during the operation of power plants, and individual heating systems operating on coal and wood [9]. One of the largest enterprises in Tomsk is a thermal power plant located almost in the center of the city.

\section{Conclusion}

The results of the isotope ratio determination presented in our work demonstrate the wide possibilities of using isotope mass spectrometry in clarifying mechanisms behind paleoclimatic and ecological problems. Information on the carbon isotope composition in peat deposits and annual tree rings makes it possible to reconstruct the climatic conditions, under which the formation of deposits and the growth of trees occurred. Isotope analysis of epiphytic mosses and lichens allows carrying out a comparative assessment of environmental pollution at spatial and temporal intervals. A study of the isotope ratios of carbon and nitrogen of atmospheric pollutants makes it possible to determine the sources of their origin and trace the ways of their propagation (migration).

The research was supported by the VIII.80.2.3 base project and the Russian Foundation for Basic Research (research project no. 16-45-700941 and no. 16-05-00521).

\section{References}

1. P. Pinho, C. Barros, S. Augusto, M. Pereira, C. Maguas, C. Branquinho, Envir. Poll., 230, 632-638 (2017)

2. O.V. Vetrova, D.A. Kalashnikova, V.N. Melkov, G.V. Simonova, Journ. of Anal. Chem., 72(7), 756-760 (2017)

3. A.T. Lebedev, Mass spectrometry for analyzing environmental objects, 632 (2013)

4. E.A. Golovatskaya, Conference proceedings "Dynamics of Modern Ecosystems in the Holocene", 133-137 (2013)

5. R. B. Alley, GISP2 Ice Core Temperature and Accumulation Data NOAA/NGDC (2004) 
6. D. McCarroll, M. H. Gagen, N. J. Loader et al., Geoch. et Cosm. Acta, 73, 1539-1547 (2009)

7. D. McCarroll, N. Loader, Quat. Scien. Rev., 23, 771-801 (2004)

8. A.N. Markelova, Y.V. Volkov, G.V. Simonova, D.A. Kalashnikova, Conference proceedings SGEM 2017, 17(41), 567-574 (2017)

9. A. Mikolajczuk, M. Berglund, B. Geypens, P. Taylor, Carbon and nitrogen isotopic ratio of the water-insoluble fraction in air filter particulate matter (Joint Research Centre Scientific and Technical Reports), 14 (2008) 